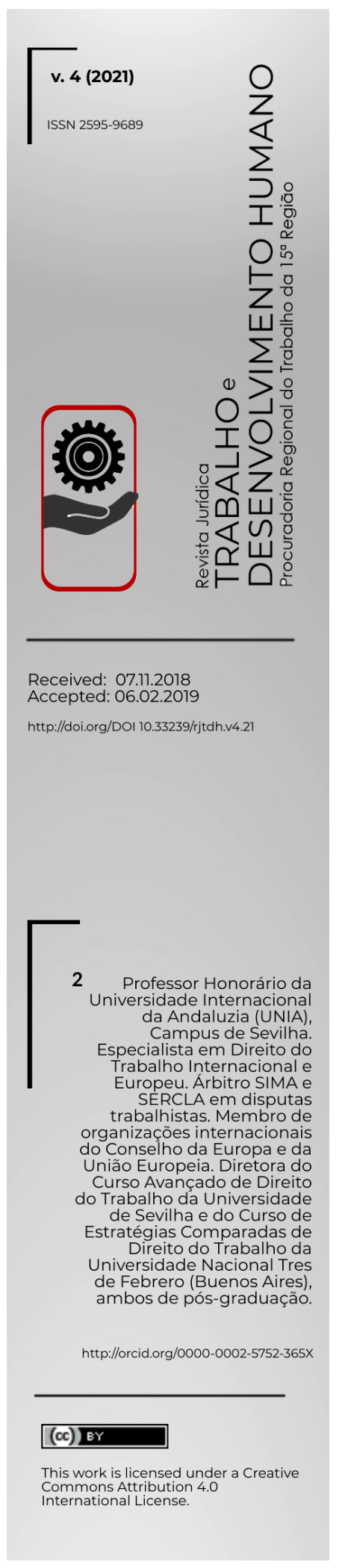

\title{
A evolução do conflito dos estivadores portuários na Espanha1
}

\author{
La evolución del conflicto de estibadores portuarios en España
}

The evolution of the conflict of dockworkers in Spain

Antonio Ojeda Avilés ${ }^{2}$

RESUMO

O artigo trata da questão do trabalho portuário na Espanha, demonstrando os caminhos pelos quais tomaram rumo o conflito entre empregados e empregadores, potencializado, neste setor, pela interferência realizada pelo Estado, e, indiretamente, pela Comunidade Europeia. Por meio de uma análise crítica e de jurisprudência comunitária, o autor demonstra que as recentes alterações na legislação portuária causaram prejuízos à classe trabalhadora, retirando-lhe condições mais favoráveis anteriormente percebidas em atendimento aos clamores da liberalização dos portos, o que vai ao encontro da livre concorrência e do princípio da "maior atratividade". Com isso, demonstra-se que a intervenção estatal espanhola na questão, por meio da edição de novos atos normativos, viola direitos previstos na Convenção 137 da OIT, ratificada pela Espanha, ao passo que sua edição é motivada pela intervenção do setor econômico na atividade pública, operacionalizada pelo governo conservador instalado no país em questão à época.

PALAVRAS-CHAVE: trabalho portuário; conflito; mediação; livre concorrência; valor social do trabalho.

\section{RESUMEN}

El artículo aborda el tema del trabajo portuario en España, demostrando las formas en que se desarrolló el conflicto entre empleados y empleadores, potenciado en este sector por la interferencia llevada a cabo por el Estado e, indirectamente, por la Comunidad Europea. A través de un análisis crítico y la jurisprudencia de la comunidad, el autor demuestra que los cambios recientes en la legislación portuaria han causado daños a la clase trabajadora, eliminando de ella las condiciones más favorables previamente percibidas en respuesta a los llamados a la liberalización de los puertos, que está en línea con la libre competencia y el principio de "mayor atractivo". Con esto, queda demostrado que la intervención estatal española en el tema, a través de la edición de nuevos actos normativos, viola los derechos previstos en el Convenio 137 de la OIT, ratificado por España, mientras que su edición está motivada por la intervención del sector económico en la actividad pública, operado por el gobierno conservador instalado en el país en cuestión en ese momento.

PALABRAS CLAVE: trabajo portuario; conflicto; mediación; libre competencia; valor social del trabajo.

\section{ABSTRACT}

The article deals with the question of port work in Spain, demonstrating the ways in which the conflict between employees and employers, fueled by the State and indirectly by the European Community, has increased. Through a critical analysis and community jurisprudence, the author

1 Tradução inédita para a língua portuguesa. Artigo original publicado na Revista Justicia Social, no 87, janeiromarço de 2017, p. 29-35. Disponível em: https://www.issuu.com/colegiooficialdegraduadossocialesde/docs/revista justicia social 87/30. Tradução e adaptação: Gabriela Costa e Silva, Mestre em Direito Público pela Universidade Federal da Bahia - UFBA, Analista Processual nos quadros do Ministério Público da União-Procuradoria Regional do Trabalho da 15a Região - Campinas/SP e Editora Assistente da Revista Jurídica Trabalho e Desenvolvimento Humano - Revista da Procuradoria Regional do Trabalho da 15a Região. Tradução e publicação aprovadas pelo autor. 
shows that the recent changes in the port legislation have caused damages to the working class, removing more favorable conditions previously perceived in response to the calls of the liberalization of the ports, which is in line with the free competition and the principle of "greater attractiveness". Thus, it is demonstrated that the Spanish intervention in the matter, by means of the edition of new normative acts, violates rights provided for in ILO Convention 137, ratified by Spain, while its edition is motivated by the intervention of the economic sector in the public activity, operated by the conservative government installed in the country in such time.

KEYWORDS: port work; conflict; mediation; free competition; social value of work.

\section{Introdução: Antecedentes}

Devido a sua estrutura geográfica como península situada na rota dos grandes cargueiros que fazem o caminho entre a China e o coração industrial da Europa, a Espanha dispõe de portos com um intenso tráfego marítimo, nos quais trabalha uma grande quantidade de estivadores em embarcadouros de avançado nível tecnológico. Há tempos, o modo de operação dos portos sofre uma profunda crise, o que é causado - e se pode dizer desde o princípio - pelo Estado, em uma intervenção atropelada pretendendo uma reconversão para a liberalização das relações de trabalho, ignorando o estabelecido pela Convenção 137/1973 da OIT ratificada por este país².

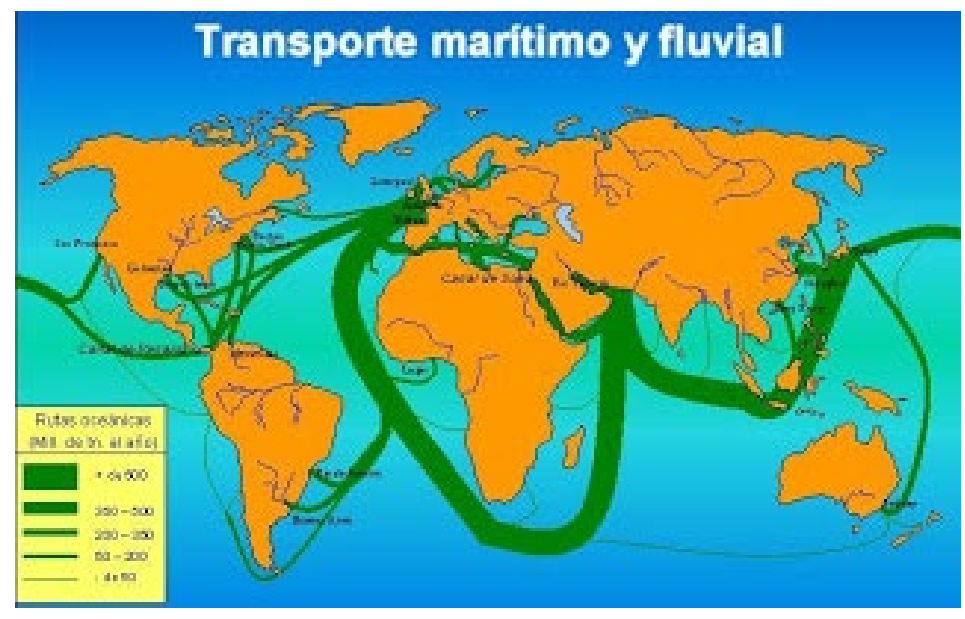

2 Uma Convenção, diga-se de passagem, que só foi ratificada por 24 países, na qual se percebem significativas ausências como Estados Unidos e China. O Brasil ratificou a Convenção em 12 de agosto de 1994. Na América Latina a ratificaram também a Costa Rica, Cuba, a Nicarágua e o Uruguai. Da União Europeia foi ratificada pela Espanha, Finlândia, França, Itália, Noruega, Polônia, Portugal, Romênia e Suécia. Pelos Países Baixos foi ratificada em 1976 e denunciada em 2006.

AVILÉS, Antonio Ojeda. A evolução do conflito dos estivadores portuários na Espanha. Revista Jurídica Trabalho e Desenvolvimento Humano, Campinas, v. 4, p. 1-20, 2021. 
Revista Jurídica Trabalho e Desenvolvimento Humano

Procuradoria Regional do Trabalho da 15a Região

O conflito entre os estivadores portuários, as empresas estivadoras e o governo atravessa praticamente todo o período do governo conservador no poder - com o Sr. Mariano Rajoy como chefe - e chega até os dias atuais, em que nos encontramos em um labirinto devido a um governo solitário que, sem a participação dos sindicatos e empresários da estiva, editou um Decreto-Lei em maio de 2017, desfazendo toda a situação anterior, mas que se mostra incapaz de interferir na regulação da estiva sem que as partes coletivas respaldem a nova estrutura. Bem é verdade que em seu apoio acudiram a Comissão Europeia e um lobby formado por um grupo seleto de empresas marítimas, a Plataforma Investidora de Portos Espanhóis (PIPE), contrária à negociação coletiva e possivelmente instigadora da intervenção do governo ${ }^{3}$. Em meio ao conflito, os meios de comunicação espanhóis há tempos já condenaram os estivadores portuários, escandalizados pelos elevados salários que aparentemente recebem, segundo um informe da consultora Price Waterhouse and Cooper (PW\&C) a instâncias da organização das grandes companhias marítimas PIPE, colocando em alerta que sua resistência em não aceitar a sentença do Tribunal de Justiça Europeu de dezembro de 2014 e o Decreto-Lei 8/2017 iria custar aos cidadãos espanhóis uma severa multa diária.

No entanto, empresários da ANESCO, a patronal majoritária do setor, e líderes do sindicato de estivadores, insistem em uníssono que o Governo havia começado por ditar, antes da norma atualmente vigente, um Decreto-Lei 4/2017, rechaçado pelo Congresso dias mais tarde ${ }^{4}$, quando ambas as partes estavam a ponto de chegar a um acordo, sem haver escutado a nenhuma delas, nem aos partidos de cujos votos necessitavam.

\footnotetext{
30 adjetivo que melhor qualifica a PIPE é o de um lobby que pressiona o governo e a opinião pública para a completa liberalização do setor portuário. Os portos espanhóis sofrem a influência de grandes bancos norteamericanos, entidades investidoras, consórcios internacionais de empresas marítimas, etc. A afirmação de que o sistema portuário espanhol prejudica as empresas estrangeiras porque impõe condições para trabalhar neles que perturbam a livre iniciativa pode ser posto à prova quando vemos que empresas como Maersk ou Cosco estão instaladas ali há tempos. De sua parte, a ANESCO é a associação empresarial majoritária entre as empresas portuárias espanholas e a celebrante de todos os acordos coletivos portuários do país, que fazem negociações em dois níveis: estatal e local, ainda que haja também acordos com empresas de outro tipo. À frente há a organização sindical esmagadoramente majoritária, a Coordenadora Estatal de Trabalhadores do Mar (CETM, antes (EEP), com uma representatividade em torno de $90 \%$.

4 Acordo do Congresso de Deputados de 16 de março de 2017 de derrogação do RDL 4/2017 (BOE de 24 de março).
}

AVILÉS, Antonio Ojeda. A evolução do conflito dos estivadores portuários na Espanha. Revista Jurídica Trabalho e Desenvolvimento Humano, Campinas, v. 4, p. 1-20, 2021. 
Revista Jurídica Trabalho e Desenvolvimento Humano Procuradoria Regional do Trabalho da 15aㅡ Região

É certo que os estivadores não são um coletivo de proletários escravizados. Mas deveria nos fazer refletir o fato de que tão elevados salários estão, não apenas pactuados com os empresários por instrumento coletivo, mas também que estes os defendem, pois preferem dispor de especialistas bem pagos e preparados do que de mão de obra variável, medianamente remunerada e desmotivada com os vertiginosos horários praticados. São especialistas que manejam grandes gruas ou sofisticados ro-ros e bobcats, e, diferentemente de outros especialistas, têm seus horários a mercê da chegada do barco, seja de noite ou de dia, e com urgência para descarregar e carregar. Daí o registro de presença a cada seis horas para render o turno ${ }^{5}$.

O problema do Ministro de Fomento do anterior governo era que esse sistema funciona. Os estivadores espanhóis são mais produtivos que outros europeus, por exemplo, que os italianos, plenamente "liberalizados", e os portos espanhóis estão entre os cinco mais produtivos da Europa, segunda a revista norte-americana JOC: em verdade, o ranking europeu estaria formado por Bremerhaven, Rotterdam, Algeciras, Barcelona e Zeebrugge.

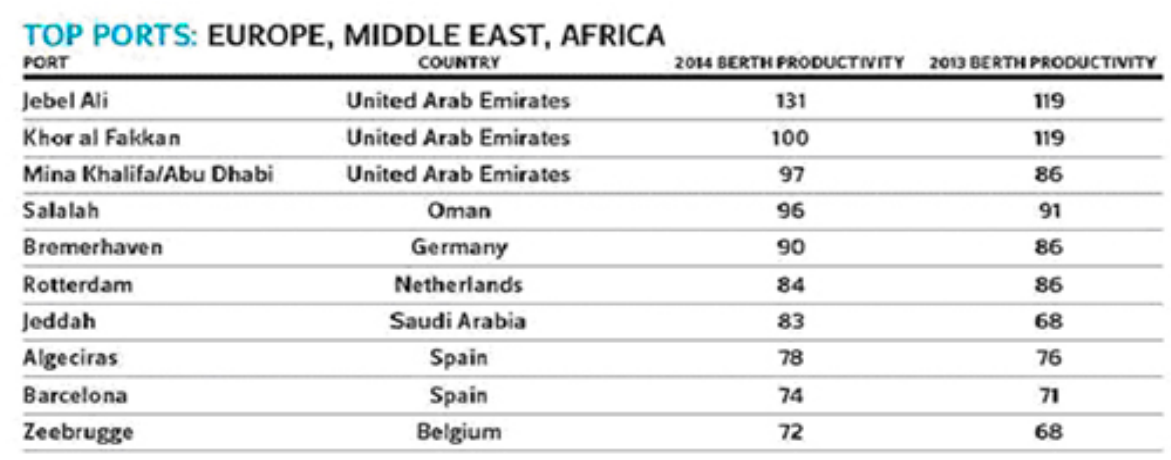

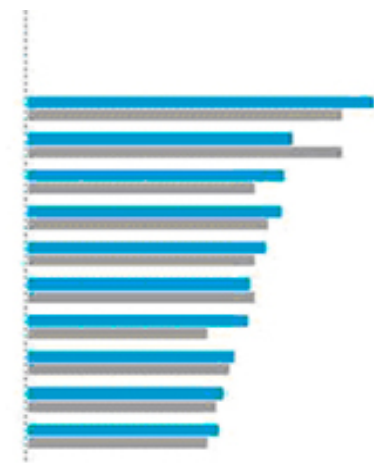

Source: fOC Port Productivity Dota, IHS Moritime \& Trode

E há 1.200 portos europeus. Não obstante, a motivação principal do vigente RDL 8/2017 parece haver sido a falta de produtividade dos portos espanhóis, se nos atemos às palavras do próprio Ministro e mediador oficial em sua proposta de mediação, que logo veremos. A aparente contradição tem sua origem, a meu ver, em uma confusão: a

5 A digitalização transformou aceleradamente esse sistema e os portuários realizam o registro hoje em dia por mensagem eletrônica.

AVILÉS, Antonio Ojeda. A evolução do conflito dos estivadores portuários na Espanha. Revista Jurídica Trabalho e Desenvolvimento Humano, Campinas, v. 4, p. 1-20, 2021. 
Revista Jurídica Trabalho e Desenvolvimento Humano Procuradoria Regional do Trabalho da 15a Região

produtividade se mede basicamente por número de contêineres manipulados no porto, enquanto que o que se aludiu por produtividade nas declarações ministeriais e mediadoras parece ter sido o rendimento por trabalhador em relação ao seu salário, ou, mais exatamente, o custo de manipulação das mercadorias, conforme o estudo realizado pela PW\&C, informação que está disponível apenas em um jornal, o qual indica que o custo laboral cobre $53 \%$ do total, além de difundir níveis de percepção salarial de cerca de 4.000 euros mensais por estivador sobre cujos parâmetros não se pode discutir porque não foram divulgados. Com semelhantes cifras, o Ministério incorporou uma crítica aos altos salários e à relação laboral especial e ditou um Decreto-Lei praticamente centrado em extinguir as SAGEP, sociedades anônimas de gestão de estiva portuária, que, em cada porto, fornecem a mão de obra às empresas estivadoras e que está formada pelas próprias empresas estivadoras, e de abolição do contrato especial de estivas pelo qual os estivadores obtinham estabilidade no emprego, tudo isso dento de um período transitório de três anos. E, não obstante, outro estudo, neste caso, público e realizado pela Universidade Politécnica de Barcelona, contradiz os resultados do estudo da PW\&C, ao avaliar o custo da mão de obra entre $14 \%$ e $21 \%$ do custo total ${ }^{6}$.

Mas voltemos ao momento anterior ao Decreto-Lei atualmente vigente, o 7/2018. Três meses antes, o governo havia pagado caro pela sua audácia quando resolveu publicar um primário e agressivo Decreto-Lei 4/2017, sem ter escutado, nem as partes negociadoras do setor, nem os partidos que lhe deviam apoiar para obter a maioria dos votos, e havendo também acolhido a solução mais traumática ${ }^{7}$. Após a maioria do Congresso ter rechaçado a sua convalidação, entrou em conversações, modificou o texto para abrandá-lo, e aí sim,

\footnotetext{
6 Os pormenores podem ser vistos no Centro de Inovação do Transporte da Universidade Politécnica da Catalunha (CENIT), Faculdade de Náutica de Barcelona" Analysis of taxes and port services costs in Ro-Ro terminals. A proposal for a cost observatory", Barcelona 2013. Versão espanhola desse estudo, na Fundação de Estudos Portuários FUNESPOR, "Estudio sobre las tasas y servicios portuarios en terminales de carga rodada. Propuesta de modelo para un observatorio de costes", Tenerife 2014.

7 Deve-se ter em conta, em honra da objetividade, que as turbulências parlamentares haviam paralisado a atividade do Parlamento desde que se havia publicado a sentença do Tribunal de Justiça Europeu (TJUE) de dezembro de 2014 no caso Comissão Europeia contra o Reino da Espanha, e o mesmo TJUE, de novo, a mando da Comissão, havia ameaçado impor uma assustadora multa dissuasória ao país para que cumprisse as recomendações da sentença. Mas o governo demorou demasiado, e quando quis intervir havia sofrido um forte castigo eleitoral e perdido a maioria, coisa que se esqueceu com o mencionado Decreto-Lei 4/2017 ao editá-lo sem haver buscado previamente os necessários apoios parlamentares, o que depois, na fase de convalidação no Parlamento, ser-lhe-iam negados, pelo "Acordo do Congresso dos Deputados de derrogação do R-D- Ley 4/2017, de 24 de fevereiro", citado supra.
}

AVILÉS, Antonio Ojeda. A evolução do conflito dos estivadores portuários na Espanha. Revista Jurídica Trabalho e Desenvolvimento Humano, Campinas, v. 4, p. 1-20, 2021. 
Revista Jurídica Trabalho e Desenvolvimento Humano Procuradoria Regional do Trabalho da 15aㅡ Região

obteve o apoio de outros partidos, conseguindo levar adiante o Decreto-Lei 8/2017, que se encontra em vigor, ainda que com aplicação paralisada em aspectos muito importantes como comentarei depois.

Em todo o caso, o governo esperou tempo demais para editar a norma. Ninguém o havia chamado nas relações portuárias que eram pacíficas, até que a Comissão denunciou a Espanha perante o Tribunal de Justiça Europeu em 2011, não se sabe ao comando de quem, ainda que os rumores apontem para o próprio Ministério de Fomento Espanhol ${ }^{8}$. Voltarei sobre esta questão mais tarde.

Tampouco as instâncias europeias permanecem livres de sombras. O Comissário dos Transportes da União Europeia tentou aplicar o mesmo regime estabelecido nos aeroportos pela Directiva 96/67 nos Estados-Membros, como se os portos marítimos fossem os mesmos, e havia fracassado em duas ocasiões - 2001 e 2004 - em suas propostas de Diretiva Portuária pela oposição frontal do Parlamento Europeu, cujo recente Regulamento 2017/352, de fevereiro, passou a estabelecer o respeito às convenções coletivas e aos direitos dos trabalhadores portuários ${ }^{9}$. E a mesma sentença condenatória contra a Espanha de dezembro de 2014 carece da profundidade a que o Tribunal Europeu nos tem acostumado, quiçá porque o juiz relator, o luxemburguês Biltgen, passou quase toda a sua vida como Ministro do governo de seu país, do partido social-cristão.

Em consequência o Decreto-Lei inicial não merecia outra coisa que sua não convalidação pelo Parlamento. Seu texto era demasiado confuso e em ocasiões incompreensível, com uma discutível solução para o tema central da "sub-rogação" nas relações trabalhistas especiais que se pretendiam derrogar: dispensas indenizadas para todo aquele que quisesse abandonar o emprego, e os demais passariam a ser contratados pelas empresas estivadoras, diretamente ou através de empresas de trabalho temporário, mas em

\footnotetext{
$8 \mathrm{Em}$ realidade, ao presidente de Portos do Estado daquele momento, a máxima autoridade competente na matéria, dependente do Ministro do Fomento. A Comissão Europeia guarda segredo sobre as denúncias que recebe a respeito dos descumprimentos dos Estados, e que dão azo para denunciá-los perante o Tribunal Europeu de Justiça.

9 Regulamento 2017/352 de 15 de fevereiro de 2017, por ele se cria um marco para a prestação de serviços portuários e se adotam normas comuns sobre a transparência financeira dos portos. Tenha-se em conta também o Regulamento (EU) 1315/2013 de 11 de dezembro de 2013 sobre as orientações da União para o desenvolvimento da Rede Transeuropeia de Transporte, pelo qual se derroga a Decisão 661/2010/UE (DO L 348 de 20.12.2013, p. 1).
}

AVILÉS, Antonio Ojeda. A evolução do conflito dos estivadores portuários na Espanha. Revista Jurídica Trabalho e Desenvolvimento Humano, Campinas, v. 4, p. 1-20, 2021. 
Revista Jurídica Trabalho e Desenvolvimento Humano Procuradoria Regional do Trabalho da 15a Região

todo caso mediante contratos temporários ${ }^{10}$. Os sindicatos resistiam em transformar alguns contratos estáveis em outros precários e pressionavam para que as empresas se substituíssem nos contratos "indeterminados" das SAGEPs. Aos mais velhos do lugar o ocorrido lhes relembra dos Decretos ditados durante os últimos anos da ditadura do general Franco, quando a conflitualidade laboral era resolvida mediante uma enérgica norma estatal que ordenava a volta imediata ao trabalho, e ninguém lhes dava importância. De qualquer modo, a multa diária de $134.000 €$ pelo atraso do governo ao cumprimento da sentença deveria esperar uma condenação que a impusesse, enquanto que as soluções do Decreto-Lei haviam custado em torno de 350 milhões de euros, também do bolso dos contribuintes. A Espanha é um país marítimo e não merecia uma regulação que bloqueasse os portos.

O atual Decreto-Lei 8/2017 diverge radicalmente do abortado 4/2017 no que tange a que uma boa parte das linhas futuras são deixadas à iniciativa das partes da negociação coletiva mediante um original - em outra parte também o chamei de 'exótico' - Anexo que incorpora a proposta de mediação e, mais especificamente, os acordos que as partes "sociais" firmaram, e que o mediador havia convertido em parte dela ${ }^{11}$. São pactos muito enérgicos, que o Governo deve transformar em um Decreto Real sem modificar nem um pouco deles, pois se diz que o Real Decreto-Lei "reunirá" nessa norma o estabelecido na proposta de mediação $^{12}$.

Esse Anexo recompõe absolutamente o equilíbrio entre as três partes em benefício da estabilidade da situação, ainda que imponha quatro novas obrigações de transcendental importância: aos empresários, para sub-rogar-se nos contratos por tempo indeterminado que

10 Habilitava-se um período transitório de três anos nos quais as empresas estivadoras se obrigavam a manter em suas folhas de pagamento um percentual decrescente de estivadores procedentes da SAGEP igual a seu percentual de participação no capital dela: $75 \%$ no primeiro ano, $50 \%$ no segundo e $25 \%$ no terceiro. Disposição Transitória Segunda do RDL 4/2017.

11 Essa parte nova constitui o Anexo ao Decreto-Lei, cujo valor é o mesmo que o deste, ou seja, valor de lei. Para maiores detalhes, veja-se o meu artigo "O exótico anexo do Real Decreto-Lei de reforma da estiva", Revista de Trabalho e Seguridade Social 424 (2018), pp. 15-41. O governo era parte da mediação e se retirou dela quando o mediador incorporou os pactos entre as outras duas partes, pelo que a rigor, como o RDL 8/2017 indica, tratase de uma "proposta" de mediação, e não um compromisso [entre as partes] por mediação.

12 Disposição Final Terceira do RDL 8/2017: “2. O governo aprovará um real decreto que retire a proposta de mediação da data de 30 de março de 2017, pela qual se põe fim a uma mediação tripartida entre as organizações sindicais, a associação empresarial e o governo".

AVILÉS, Antonio Ojeda. A evolução do conflito dos estivadores portuários na Espanha. Revista Jurídica Trabalho e Desenvolvimento Humano, Campinas, v. 4, p. 1-20, 2021. 
os estivadores tiverem com a respectiva SAGEP ${ }^{13}$; aos sindicatos, a obrigação de reconhecer o poder de direção e organização dos empresários no trabalho portuário ${ }^{14}$; ao governo, o reconhecimento de uma aposentadoria antecipada bastante favorável aos estivadores de idade avançada, em particular para aqueles para os quais faltavam sessenta meses ou menos para alcançar a idade de aposentadoria ordinária ${ }^{15}$; e a todos a obrigação de respeitar a convenção coletiva setorial de máximo nível nos capítulos referentes aos aspectos mais delicados da relação laboral, como condições de trabalho, modalidades de tarefas, jornada e descanso, ou formação, prevenção e igualdade ${ }^{16}$. Em contrapartida, se incorporava ao Decreto-Lei uma disposição que dotava as convenções coletivas de cada porto de uma eficácia superior a das convenções superiores, e nomeadamente a de máximo nível ${ }^{17}$.

O governo conservador caiu quando o presidente, Mariano Rajoy, foi submetido a uma moção de censura vitoriosa, e atualmente a Espanha tem um governo progressista que trata de digerir todo o ocorrido e articular esse Decreto de desenvolvimento com os compromissos que contêm. Encontramo-nos em uma expectativa que ao dia de hoje dura já mais que um ano. Neste ínterim será bom que analisemos todo o contexto comunitário de onde nasce formalmente o impulso à reforma em marcha.

\footnotetext{
13 Anexo do RDL 8/2017, Anexo A. Tenha-se em conta que tal sub-rogação havia sido pactuada pela associação de empresários e os sindicatos participantes na mediação, e por isso havia sido aceito de plano pelos primeiros. Este ponto contrasta agudamente com o espírito do RDL, que previa a incorporação dos estivadores às empresas de trabalho temporário e à contratação mediante contratos temporários que deixavam no vazio os tempos entre as missões.

14 Anexo do RDL 8/2017, Anexo B, passim.

15 Anexo do RDL 8/2017, Apartado C.

16 Anexo do RDL 8/2017, Apartado B, parágrafo 10.

17 Disposição Adicional Segunda do RDL 8/2017. A incorporação ex novo desta norma deve se colocar em relação com a criação pelo governo conservador na Lei 3/2012 da prioridade aplicativa das negociações com a empresa em caso de conflito com as negociações de âmbito superior e referente às matérias do sinalagma contratual, um fenômeno que se repetiu, inclusive com mais força, na Itália e também na França, e que no Brasil teve igualmente expressão na reforma do presidente Temer com a Lei 13.467/2017.
}

AVILÉS, Antonio Ojeda. A evolução do conflito dos estivadores portuários na Espanha. Revista Jurídica Trabalho e Desenvolvimento Humano, Campinas, v. 4, p. 1-20, 2021. 


\section{A regulação comunitária}

Assim sendo, o Ministro de Fomento esteve consciente de que uma nova intervenção por via do Decreto-Lei restaria amortizada caso não contasse com o respaldo dos atores em conflito e com a maioria do Parlamento, e expressou sua disposição em esperar por um possível acordo entre as partes.

Mas, sobre que problemas se debatia e ainda se debate?

Primeiro de tudo, acerca da aplicação do regulamento europeu sobre portos europeus, o acórdão do Tribunal de Justiça Europeu, no caso Comissão Europeia contra a Espanha, entende infringido pela existência em nosso país das empresas de gestão do trabalho do trabalho portuário (SAGEP) financiadas compulsoriamente pelas empresas às quais os estivadores devem pertencer e para as quais as empresas acima mencionadas devem obrigatoriamente recorrer para as suas necessidades temporárias de mão de obra. $\mathrm{Na}$ realidade, as SAGEP atuam como empresas de trabalho temporário, fornecendo às empresas de cada porto a mão de obra conjuntural que necessitam, enquanto que para os estivadores envolvidos em tal rodízio os mantêm em uma "relação laboral especial" cuja peculiaridade consiste em permitir-Ihes uma estabilidade salarial por via de abonar-Ihes durante os dias de greve - graças ao financiamento oferecido proporcionalmente pelas empresas portuárias um "salário de inatividade" ou "garantia de percepção salarial" que vem a equivaler ao seguro por desemprego.

Encontramo-nos, consequentemente, frente a uma condenação coletiva das listas de estivadores reconhecidos, também denominadas como registros, pools ou bolsas de trabalho portuário, uma prática reconhecida na maioria dos portos europeus e à qual a decidida oposição da Comissão Europeia vem diminuindo o apoio desde sua sentença sobre o porto de Gênova em $1997^{18}$.

A sentença do Tribunal Europeu contra a Espanha se traduz em um apotegma e quatro deduções. No primeiro lugar, a sentença considera que a legislação espanhola sobre portos

18 Sentença TJUE 179/90, de 10 de janeiro de 1991, caso Porto di Genova. A seu teor, as operações de estiva e as portuárias em geral carecem de interesse econômico geral e consequentemente estão submetidas às normas comunitárias sobre livre concorrência e liberdade de circulação. 
Revista Jurídica Trabalho e Desenvolvimento Humano Procuradoria Regional do Trabalho da 15ㄹ Região

infringe a legislação europeia, em particular o art. 49 do Tratado de Funcionamento, por "fazer menos atrativo o exercício, por parte dos nacionais comunitários, da livre iniciativa garantida pelo Tratado" ${ }^{19}$; em segundo, a parte decisória da sentença destrincha os quatro descumprimentos do Reino da Espanha: impõe às empresas de outros Estados membros ainda que em igualdade de condições com quaisquer empresas - a obrigação de inscrever-se nas SAGEPs e de participar no capital destas, assim como a obrigação de contratar prioritariamente os trabalhadores das listas delas e um mínimo de tais empregados como empregados permanentes.

Dessa maneira a sentença europeia condena a Espanha porque sua legislação deixa "menos atrativa" a liberdade de iniciativa no país para as empresas de outros países europeus, mesmo que estas estejam obrigadas às mesmas prestações às quais se vêm obrigadas as espanholas. Trata-se, como vemos, de uma questão de matiz, em que nenhum papel desempenha a não discriminação, pois todos devem pertencer e pagar as SAGEP, e não apenas as empresas tão ambiguamente chamadas "comunitárias". Sobre o escorregadio princípio da escassa atratividade, que poderíamos traduzir, se me for permitida a ocorrência, por "allegro ma non troppo", a sentença remete a várias outras que tratam de definir o indefinível, os limites do pouco-tentador-mas-em-princípio-válido ${ }^{20}$, assim como a uma Comunicação sobre política portuária europeia, a COM (2007) 616, a cujo teor as disposições sobre contratação de trabalhadores portuários não devem se utilizar para impedir que pessoas ou empresas devidamente qualificadas prestem serviços de manipulação de mercadorias ou para impor aos empresários uma mão de obra das quais não necessitam.

Tal é a legislação comunitária que se estima infringida: uma doutrina jurisprudencial que protege a livre iniciativa inclusive nos evanescentes e imprecisos limites do pouco atrativo, e uma Comunicação que carece de valor normativo, mas que em definitivo só poderia ter relevância no que diz respeito à imposição de mão de obra desnecessária, esse percentual de

19 Sentença 576/13, apartado "Sobre el recurso", parágrafo 2‥

20 Em verdade, as sentenças TJUE Kraus 19/92, Comisión c. Países Bajos 299/02, y Comisión c. Grecia 140/03, citadas no item "Sobre el recurso", parágrafo 2, assim como as sentenças Comisión contra Francia 89/09, y SOA Nazionale Costruttori 372/12, citadas neste mesmo item "Sobre el recurso", páragrafo 11. 
contratações por tempo indeterminado que a autoridade portuária estabelece para cada empresa ao outorgar a licença de exploração ${ }^{21}$.

$\mathrm{Na}$ sua luta pela liberalização empresarial dos portos, a Comissão parece estar absolutamente só. Fracassou em duas ocasiões nos seus intentos para conseguir a aprovação de uma Diretriz nesse sentido, e a jurisprudência sobre o caso particular, podemos qualificála como pírrica, pois frente às sentenças que a apoiam, basicamente a do caso Porto di Genova, encontramos outras que defendem o contrário, a saber, que nos situamos ante de atividades de interesse geral e que as normas comunitárias não são de aplicação à estiva. Nessa jurisprudência enfrentada é onde encontramos uma chave importante no desenvolvimento argumentativo que condena a Espanha, pois estou falando principalmente da sentença Becu e outros, C-22/98, que resolvia a questão de se as listas de estivadores se chocavam com a legislação comunitária sobre a livre concorrência, concluindo-se pela negativa. Desse modo, o caminho para uma condenação - digamos assim - normal, em torno da possível infração à livre concorrência, permanecia cerceado, levando a Comissão a tentar a muito mais complexa e discutível, via de infração da liberdade de estabelecimento (livre iniciativa) do art. 49 do TFUE (Tratado sobre o Funcionamento da União Europeia). A sentença Becu não só explica os tortuosos caminhos da condenação à Espanha, mas também entra no âmago da regulação sobre bolsas de trabalho ou pools como o das SAGEP: a lei belga de 08 de junho de 1972 proibia e proíbe "a execução de todo trabalho portuário nas zonas portuárias por trabalhadores distintos dos trabalhadores portuários reconhecidos", sendo que uma empresa estivadora do porto de Gante dirigida pelo senhor Becu havia a infringido contratando trabalhadores externos, o que havia gerado uma denúncia criminal pela fiscalização de Gante e uma questão prejudicial do tribunal ante o TJUE. Pois bem, o TJUE rechaçou a possibilidade de evitar a proibição, deixando a porta aberta ao juiz local para condenar criminalmente a Becu e os demais envolvidos, entendendo que a livre concorrência do Direito Europeu não permite às empresas portuárias se oporem à obrigação de "empregar exclusivamente trabalhadores portuários reconhecidos" e a "pagar a estes uma retribuição que supera

21 Art. 117.1, letra n), da Lei de Portos do Estado (RDLeg 2/2011), que veio derrogada pelo RDL 4/2017, por sua vez derrogado - não convalidado pelo Congresso, como sabemos. Diz assim: “n) Nas licenças de serviço portuário de manipulação de mercadorias, percentual mínimo de trabalhadores que devem ser contratados em regime de trabalho comum".

AVILÉS, Antonio Ojeda. A evolução do conflito dos estivadores portuários na Espanha. Revista Jurídica Trabalho e Desenvolvimento Humano, Campinas, v. 4, p. 1-20, 2021. 
Revista Jurídica Trabalho e Desenvolvimento Humano Procuradoria Regional do Trabalho da 15aㅡ Região

amplamente os salários de seus próprios empregados ou os que pagam a outros trabalhadores". Retorcendo os conceitos, a condenação à Espanha se inspira na mesma ideia que havia saído derrotada na sentença Becu e à livre concorrência, para fazê-la prevalecer em respeito ao princípio da liberdade de estabelecimento, pois em realidade, o motivo do "menor atrativo" em se estabelecer era o do custo econômico e mais concretamente o do custo salarial, cuja diferença com o "normal" se considerava como uma diferença "não equitativa" 22

Ademais, o Advogado Geral proponente na sala do Tribunal de Justiça era o espanhol Ruiz Jarabo, quem teve a satisfação de ver confirmadas suas teses pela sentença que se acabou de comentar. Dizia em suas conclusões que:

Da análise dos autos não se desprende elemento algum capaz de desvirtuar o caráter exclusivamente laboral que reveste a relação jurídica no marco da qual os trabalhadores reconhecidos da zona portuária de Gante prestam seus serviços, nem a existência de forma organizativa alguma suscetível de ser considerada como uma empresa aos efeitos das normas comunitárias sobre a concorrência.

A luta parece ter sido finalmente perdida pela Comissão, apesar da condenação da Espanha, pela promulgação do recente Regulamento sobre portos $217 / 352$, que merece comentário específico nas linhas que seguem.

2. O Regulamento comunitário $217 / 253$, de 15 de fevereiro, sobre prestação de serviços portuários

Dois anos depois da sentença condenatória, o Parlamento e o Conselho Europeus promulgaram um Regulamento pelo qual se criava um marco para a prestação de serviços

22 Sentença Becu e outros 22/98, parágrafo 15: o juiz de primeira instância havia entendido como não equitativa a diferença salarial entre a percepção do trabalhador ordinário na empresa SMEG, de 667 francos belgas a hora, e a dos estivadores reconhecidos dentro da mesma empresa, de 1335 francos belgas a hora, mais que o dobro, pelo que havia rechaçado a imputação da fiscalização. Junto a essa diferença salarial, provavelmente jogaria a favor do não conhecimento do caráter penal das sanções contempladas pela Lei de 1972. Recorrida a decisão em segunda instância, o novo tribunal havia abordado a questão prejudicial ante o TJUE antes de resolver.

AVILÉS, Antonio Ojeda. A evolução do conflito dos estivadores portuários na Espanha. Revista Jurídica Trabalho e Desenvolvimento Humano, Campinas, v. 4, p. 1-20, 2021. 
portuários e se adotavam normas comuns sobre a transparência financeiras dos portos, onde uma extensa e importante exposição de motivos dá passo a um capítulo central, o 2으, com regras de capital importância sobre a estiva ao versar sobre a prestação de serviços portuários, um capítulo que, não obstante, acaba com um giro inesperado.

A importância desses artigos radica em que contemplam a possibilidade de que a prestação de serviços portuários por parte das empresas interessadas possa estar submetida a requisitos mínimos da dita prestação, à limitação do número de prestações, a obrigações de serviço público ou a restrições relacionadas com operadores internos. Dentro dos requisitos mínimos diz, ademais, que poderão consistir em manter as equipes necessárias para prestar o serviço em condições normais e seguras ou na capacidade para prestá-lo sem interrupções durante todo o ano, ou em certas qualificações profissionais, requisitos mínimos que terão como condição indispensável ser transparentes, objetivos, não discriminatórios e pertinentes para o serviço de que se trate ${ }^{23}$. A princípio, as referências, por mais genéricas que pareçam, relembram-nos sobre os problemas principais que se elucidam no conflito da estiva, às SAGEP com sua bolsa prioritária na contratação e ao serviço de manipulação de cargas a qualquer hora durante todo o ano.

O art. 7ำ do Regulamento menciona algumas regras do serviço público que podem ser impostas às empresas portuárias, como a continuidade ou a não interrupção do serviço, a segurança das operações, a igualdade e a universalidade dos usuários do serviço - as carregadeiras ou companhias marítimas-, e também um preço acessível para determinadas categorias de usuários. Alude o Regulamento, no artigo seguinte, à possibilidade de realizar tais prestações de serviço público por meio de um operador interno que, não obstante, parece consistir em uma entidade autônoma, ainda que plenamente subordinada à hierarquia portuária, pois a autoridade competente há de exercer sobre esse organismo gestor do porto "um grau de controle [...] similar ao que tem sobre seus próprios departamentos", ou, em outros termos, "tem-se uma influência decisiva tanto sobre os objetivos estratégicos como sobre as decisões importantes da entidade jurídica de que se trata". Se lembrarmos de que as SAGEP espanholas têm um funcionamento muito similar ao das ETT24, compostas, financiadas

23 Artículo 4 del Reglamento.

24 Empresas de Trabajo Temporal - Nota da Tradutora.

AVILÉS, Antonio Ojeda. A evolução do conflito dos estivadores portuários na Espanha. Revista Jurídica Trabalho e Desenvolvimento Humano, Campinas, v. 4, p. 1-20, 2021. 
e dirigidas pelas empresas portuárias que elegem seus órgãos diretivos, não parece factível considerá-las como operadores internos totalmente controlados pela autoridade portuária. A questão a resolver consiste, pois, em saber se as gestoras de mão de obra controladas pelas empresas portuárias têm lugar no marco estabelecido pelo Regulamento Comunitário. Mas essa questão tem direto encaixe no surpreendente final de que havia falado antes.

O Regulamento alude também à possibilidade de sub-rogação, pois indica no art. 9o que em caso de mudança de prestador de serviços portuários, a autoridade competente poderá exigir à nova empresa portuária que se sub-rogue nos direitos e obrigações trabalhistas da anterior.

Todo o anterior parece propenso a admitir uma situação como a dos portos espanhóis - e, caberia adicionar, como a da maioria dos portos europeus -, com suas SAGEPs compulsoriamente financiadas por recurso das empresas portuárias e com estivadores em uma relação especial que consiste em um contrato indeterminado e bem remunerado.

A nota final do Capítulo 2, mencionada anteriormente, nos leva a uma ruptura sem saída porque vem a anular todo o anterior porquanto se refere aos estivadores. "O disposto no presente capítulo e no artigo 21 - diz - não se aplicará aos serviços de manipulação de carga, aos serviços de passagem nem à pilotagem". Provavelmente pela variedade de soluções nacionais, com predomínio dos registros unitários ou bolsas internas de trabalho, que, além disso, vêm respaldadas pela Convenção 137 da OIT, o Regulamento deixa liberdade aos portos para organizar estes serviços como considerem mais oportuno, deixando que convivam as sentenças contraditórias que vimos, do Porto di Genova, do Porto de Gante ("Becu e outros") e da Comissão Europeia contra a Espanha.

\section{A proposta de mediação e a resposta das partes}

Surpreendentemente a proposta de mediação oferecida em 30 de março de 2017 às partes pelo presidente do Conselho Econômico e Social, D. Marcos Peña, omite toda referência às possíveis mudanças normativas aportadas pelo Regulamento da UE, embora este tivesse aparecido publicado no Diário Oficial da União Europeia quase um mês antes. Menciona unicamente a necessidade de estabelecer "um novo marco regulador, derivado da 
Sentença [europeia] e aos critérios de ordenação da atividade empresarial contidos no ordenamento da $\mathrm{UE}^{\prime 25}$.

$\mathrm{Na}$ realidade, a sentença e os critérios de ordenação da atividade empresarial do Direito Social Europeu significam bem pouca coisa. Já vimos como o TJUE declara o descumprimento de um artigo do Tratado de Funcionamento, ao não haver regulamento ou Diretriz sobre o caso particular, e o faz em virtude do "menor atrativo" que supõe se estabelecer nos portos espanhóis, com base na obrigação das empresas de pertencer às SAGEP, participar de seu financiamento, empregar os estivadores da sua lista, e contratar por tempo indeterminado uma porcentagem indicada pela autoridade portuária igualmente dentro da lista da SAGEP. No que diz respeito aos critérios de gestão da atividade comercial constantes no Ordenamento da UE, o mediador declara expressamente o regulamento relativo à transferência de empresas e dispensas coletivas, bem como o princípio do equilíbrio entre a liberdade das empresas e os direitos sociais e de emprego.

No entanto, além do acervo comunitário, incluindo-se nisso o que fora incluso por ele mesmo, o mediador parte de dois pressupostos que influem decisivamente em sua proposta: de uma parte, que a sentença é clara quanto aos termos da condenação; de outra parte, que se pode partir de um marco empresarial como o desenhado pelo derrogado RDL 4/2017 na hora de conduzir uma cessão de trabalhadores em termos similares aos que eram desempenhados nos termos da norma anterior, ainda que não haja uma fórmula de continuidade no emprego que suponha a sub-rogação direta a respeito de cada empresa ${ }^{26}$. Que a sentença da UE permite diversas interpretações já foi discutido por autores como VILLAR, quando este afirma que o registro único ou pool de estivadores, assim como a preferência no emprego ou a adequação às necessidades não requerem que as empresas portuárias devam filiar-se às SAGEP, nem a obrigação de contratar exclusivamente com elas, nem por uma equipe mínima ${ }^{27}$, ou em termos mais gerais por VAN HOOYDONKE quando

25 PEÑA PINTO M., "Propuesta de mediación sobre efectos laborales de la nueva ordenación laboral del servicio portuario de manipulación de mercancías", Madrid 30 de marzo de 2017, p. 5.

26 Ibidem, pp. 6-7.

27 VILLAR ROJAS F.J., "La libertad europea de establecimiento: restricciones justificadas y no justificadas. (A propósito de la STJUE sobre la estiba en los puertos españoles)",enWAA.,Derecho Administrativo e Integra ción Europea, Ed. Reus, Madrid, 2017, p. 14.

AVILÉS, Antonio Ojeda. A evolução do conflito dos estivadores portuários na Espanha. Revista Jurídica Trabalho e Desenvolvimento Humano, Campinas, v. 4, p. 1-20, 2021. 
afirma que o Direito da União permite aos Estados membros escolher entre o trabalho portuário livre ou um sistema sustentável de pool ou o registro de estivadores que não esteja submetido a restrições excessivas ${ }^{28}$.

Dentro desses limites, a proposta do mediador pode ser estimada moderadamente positiva, até o ponto de quase obter a aprovação de ambas as partes. Em substância propõe quatro pontos principais:

a) A sub-rogação das novas gestoras de emprego portuário nas relações de trabalho atuais que mantêm as respectivas SAGEP com os estivadores, conforme o estabelecido no art. 44 do Texto Refundido ET. As fórmulas concretas da sub-rogação seriam negociadas por ambas as partes, e em seu caso, refletidas na negociação coletiva ${ }^{29}$. Trata-se de uma proposta cuja parte mais complexa, a determinação das fórmulas específicas para a transferência de pessoal às novas gestoras de emprego portuário - sejam ETTs ou Centros Portuários de Emprego -, distancia radicalmente ambas as partes, pelo que a negociação e sua concretização por meio de acordos coletivos teriam grandes possibilidades de fracassar.

b) Negociação pelas partes das medidas de flexibilidade que permitiriam às empresas portuárias assumir o controle das contratações, abandonando os sistemas de cessão direta pelas SAGEP, e que nos atuais acordos coletivos costumam seguir a fórmula do rodízio ${ }^{30}$.

c) Manutenção da oferta do Governo de ajudas à aposentadoria antecipada voluntária para os estivadores dentro dos sessenta meses prévios à aposentadoria ordinária, com prestações equivalentes a 70\% da média salarial e contribuições por meio de acordo específico.

d) Redução dos salários em 10\% para aqueles que tivessem soldos superiores ao triplo do salário mínimo, medida interprofissional que poderia substituir-se mediante acordo por outra ou por outras medidas de flexibilidade interna.

28 Port labour in the EU, Bruselas 2013, p. 2.

29 Propuesta del mediador, p. 10.

300 texto do mediador, p. 11, alude a uma prática consolidada durante decênios denominada "pacto de mãos e destino", que viria a ser rompido pela cessão do controle das empresas portuárias fixadas em acordos coletivos futuros. Mas se os atuais acordos estabelecem o rodízio de efetivos - como ocorre similarmente nas bolsas de trabalho de outras atividades, por exemplo, na saúde - e ditos pactos burlam o pactuado, mal parece que vão desaparecer pelo mero feito de estabelecerem os futuros acordos um sistema, já não de rodízio, mas sim de cessão direta do controle à empresa.

AVILÉS, Antonio Ojeda. A evolução do conflito dos estivadores portuários na Espanha. Revista Jurídica Trabalho e Desenvolvimento Humano, Campinas, v. 4, p. 1-20, 2021. 
A resposta das partes chegou ao mediador por cartas da ANESCO e dos sindicatos, ambas datadas de 04 de abril. A proposta recebida agradou as empresas, ainda que condicionem sua aceitação ao esclarecimento do marco jurídico, ou melhor, ao esclarecimento sobre se a futura norma manterá ou não "todos os termos do RDL derrogado, e em especial, sobre seu regime transitório", assim como o alcance real do plano de ajudas do Governo às pré-aposentadorias. Aos Sindicatos preocupa a garantia de $100 \%$ dos empregos aos estivadores atuais, e requerem reconhecer os planos normativos do governo antes de aceitar a proposta, assim como os dados concretos das ajudas, por porto e por trabalhador.

\section{Conclusões e proposta}

Ao momento de escrever essas linhas, parece muito difícil alcançar uma norma capaz de abrir uma via de solução, principalmente por causa da atitude do Ministério de esperar pela negociação coletiva, enquanto que a negociação coletiva espera pela publicação do Decreto que resolva em especial o tema das aposentadorias antecipadas.

A sentença do TJUE pode ser interpretada de diversas maneiras, como já vimos, e, em minha opinião, uma boa resposta a seus requerimentos poderia consistir em não obrigar as empresas portuárias a pertencer forçosamente às SAGEP, as quais poderiam passar a ser gestoras portuárias de emprego que recebem uma taxa daquelas pela cessão de mão de obra. A relação especial de emprego dos estivadores com as SAGEP e sua formação e segurança laboral deveria ajustar-se ao que fosse obtido com tais tarifas, que teriam um componente de serviço público para garantir a continuidade dos serviços. Esta proposta poderia satisfazer as exigências do Tribunal Europeu, ainda que se considere poder haver alternativas que não perpassem pela necessidade de entrar na questão das complicadas sub-rogações. O requisito é, como sempre, a vontade.

\section{Referências}

AVILÉS, Antonio Ojeda. El exótico anexo del Real Decreto-ley de reforma de la estiba. In: REVISTA DE TRABAJO Y SEGURIDAD SOCIAL, n. 424. jul/2018. Disponível em: 
Revista Jurídica Trabalho e Desenvolvimento Humano

https://www.laboral-social.com/exotico-anexo-real-decreto-ley-reforma-estiba.html. Acesso em: 5 nov. 2018.

BRASIL. LEI No 13.467, DE 13 DE JULHO DE 2017. Altera a Consolidação das Leis do Trabalho (CLT), aprovada pelo Decreto-Lei no 5.452, de 1 o de maio de 1943, e as Leis nos 6.019, de 3 de janeiro de 1974, 8.036, de 11 de maio de 1990, e 8.212, de 24 de julho de 1991, a fim de adequar a legislação às novas relações de trabalho. Disponível em:

http://www.planalto.gov.br/ccivil 03/ ato2015-2018/2017/lei/L13467.htm. Acesso em:

5 nov. 2018.

COMISSÃO EUROPEIA; VAN HOOYDONK, Eric. PORT LABOUR IN THE EU - Labour Market, Qualifications \& Training, Health \& Safety. [s.l.: s.n.], 2013. Disponível em:

https://ec.europa.eu/transport/sites/transport/files/modes/maritime/studies/doc/2013-0108-ec-port-labour-study-vol2.pdf.

ESPANHA. Real Decreto Legislativo 2/2011, de 5 de septiembre, por el que se aprueba el Texto Refundido de la Ley de Puertos del Estado y de la Marina Mercante. 2011. Disponível em: https://www.boe.es/buscar/doc.php?id=BOE-A-2011-16467. Acesso em: 5 nov. 2018.

ESPANHA. Real Decreto-ley 4/2017, de 24 de febrero, por el que se modifica el régimen de los trabajadores para la prestación del servicio portuario de manipulación de mercancías dando cumplimiento a la Sentencia del Tribunal de Justicia de la Unión Europea de 11 de diciembre de 2014, recaída en el asunto C-576/13 (procedimiento de infracción 2009/4052). 2017a. Disponível em: https://www.boe.es/buscar/doc.php?id=BOE-A-2017-1933.

ESPANHA. Real Decreto-ley 8/2017, de 12 de mayo, por el que se modifica el régimen de los trabajadores para la prestación del servicio portuario de manipulación de mercancías dando cumplimiento a la Sentencia del Tribunal de Justicia de la Unión Europea de 11 de diciembre de 2014, recaída en el Asunto C-576/13 (procedimiento de infracción 2009/4052). 2017c. Disponível em: https://www.boe.es/buscar/doc.php?id=BOE-A-2017-5270. Acesso em: 5 nov. 2018.

ESPANHA. Resolución de 16 de marzo de 2017, del Congreso de los Diputados, por la que se ordena la publicación del Acuerdo de derogación del Real Decreto-ley 4/2017, de 24 de febrero, por el que se modifica el régimen de los trabajadores para la prestación del servicio portuario de manipulación de mercancías dando cumplimiento a la Sentencia del Tribunal de Justicia de la Unión Europea de 11 de diciembre de 2014, recaída en el asunto C-576/13 (procedimiento de infracción 2009/4052). 2017b. Disponível em: https://www.boe.es/boe/dias/2017/03/24/pdfs/BOE-S-2017-71.pdf.

FUNESPOR. Estudio sobre las Tasas y Servicios Portuarios en Terminales de Carga Rodada (ene. 2014). 2014. Disponível em: http://funespor.org/documentos/centrodocumentacion/estudios-de-funespor/estudio-sobre-las-tasas-y-servicios-portuarios-enterminales-de-carga-rodada/detail. Acesso em: 5 nov. 2018. 
Revista Jurídica Trabalho e Desenvolvimento Humano Procuradoria Regional do Trabalho da 15aㅡ Região

ORGANIZAÇÃO INTERNACIONAL DO TRABALHO. Convenio C137 - Convenio sobre el trabajo portuario, 1973 (núm. 137). 1973. Disponível em:

https://www.ilo.org/dyn/normlex/es/f?p=NORMLEXPUB:12100:0::NO::P12100 ILO CODE:C 137. Acesso em: 5 nov. 2018.

CONSELHO DA UNIÃO EUROPEIA. PARLAMENTO EUROPEU. DECISIÓN No 661/2010/UE DEL PARLAMENTO EUROPEO Y DEL CONSEJO, De 7 De Julio De 2010, Sobre Las Orientaciones De La Unión Para El Desarrollo De La Red Transeuropea De Transporte (Refundición). Bruxelas, 2010. Disponível em: https://eur-lex.europa.eu/legalcontent/ES/TXT/HTML/?uri=CELEX:02010D0661-20131221\&from=FR. Acesso em: 5 nov. 2018.

PARLAMENTO EUROPEU; CONSELHO DA UNIÃO EUROPEIA. REGLAMENTO (UE) 2017/352 DEL PARLAMENTO EUROPEO Y DEL CONSEJO, de 15 de febrero de 2017, por el que se crea un marco para la prestación de servicios portuarios y se adoptan normas comunes sobre la transparencia financiera de los puertos. 2017. Disponível em: https://eurlex.europa.eu/legal-content/ES/TXT/?uri=CELEX\%3A32017R0352. Acesso em: 5 nov. 2018.

PARLAMENTO EUROPEU; CONSELHO DA UNIÃO EUROPEIA. Reglamento (UE) $n^{\circ}$ 1315/2013 del Parlamento Europeo y del Consejo, de 11 de diciembre de 2013, sobre las orientaciones de la Unión para el desarrollo de la Red Transeuropea de Transporte, y por el que se deroga la Decisión $n^{\circ}$ 661/2010/UE. Bruxelas, 2013. Disponível em: https://eur-lex.europa.eu/legalcontent/ES/ALL/?uri=CELEX\%3A32013R1315. Acesso em: 5 nov. 2018.

PEÑA, PINTO M. "Propuesta de mediación sobre efectos laborales de la nueva ordenación laboral del servicio portuario de manipulación de mercancías", In: Justicia Social, Madrid, 30 de marzo de 2017, p. 5.

UNIÃO EUROPEIA. Directiva 2001/23/CE del Consejo, de 12 de marzo de 2001, sobre la aproximación de las legislaciones de los Estados miembros relativas al mantenimiento de los derechos de los trabajadores en caso de traspasos de empresas, de centros de actividad o de partes de empresas o de centros de actividad. Bruxelas, 2001. Disponível em:

http://noticias.juridicas.com/base datos/Laboral/LE0000102497 20151009.html. Acesso em: 5 nov. 2018.

UNIÃO EUROPEIA. Directiva 98/59/CE del Consejo de 20 de julio de 1998 relativa a la aproximación de las legislaciones de los Estados miembros que se refieren a los despidos colectivos. OJ L 225, 12.8.1998, p. 16-21. Bruxelas, 1998. Disponível em: http://data.europa.eu/eli/dir/1998/59/oj/spa. Acesso em: 5 nov. 2018.

TRIBUNAL DE JUSTIÇA DA UNIÃO EUROPEIA. C-22/98 - Sentencia Del Tribunal De Justicia (Sala Sexta) De 16 De Septiembre De 1999. Bruxelas, 1998. Disponível em: http://curia.europa.eu/juris/document/document.jsf?text=\&docid=44708\&pagelndex=0\&do clang=ES\&mode=Ist\&dir=\&occ=first\&part=1\&cid=22049. Acesso em: 5 nov. 2018. 
TRIBUNAL DE JUSTIÇA DA UNIÃO EUROPEIA. Sentencia 576/13 - Sentencia Del Tribunal De Justicia (Sala Sexta) De 11 De Diciembre De 2014. Disponível em:

http://curia.europa.eu/juris/document/document.jsf?docid=160562\&doclang=EOS.

Bruxelas, 2014. Acesso em: 5 nov. 2018.

TRIBUNAL DE JUSTIÇA DA UNIÃO EUROPEIA. Sentencia TJUE 179/90, de 10 de diciembre de 1991, caso Porto di Genova. Disponível em: https://eur-

lex.europa.eu/resource.html?uri=cellar:67aad9fb-aac3-4257-ae39-

9ed8928531af.0008.02/DOC 1\&format=PDF.

VILLAR ROJAS F.J., "La libertad europea de establecimiento: restricciones justificadas y no justificadas. (A propósito de la STJUE sobre la estiba en los puertos españoles)", In: Derecho Administrativo e Integración Europea, Ed. Reus, Madrid, 2017, p. 14. 